Original Research Paper

\title{
Control of Incoming H2/O2 Flows in a PEM Fuel Cell
}

\author{
Dhia Mzoughi, Nabila Khili, Hatem Allagui and Abdelkader Mami \\ Analysis, Conception and Control Systems Laboratory-ENIT, Campus Universitaire- El Manar-Tunis, Tunisia
}

Article history

Received: 7-12-2014

Revised: 31-12-2014

Accepted: 13-01-2015

Corresponding Author: Dhia Mzoughi

Analysis, Conception and Control Systems LaboratoryENIT, Campus UniversitaireEl Manar-Tunis, Tunisia E-mail: dhia.mzoughi@gmail.com

\begin{abstract}
It has become crucial, with the dwindling of energy resources related to the depletion risk of fossil and fissile resources, to find energy alternatives which have the same properties as those of a hydrocarbon in terms of transport and storage. In this context, the fuel cell appears as a very serious element both at the industrial and research levels. The aim of the manuscript is to highlight the bond graph representation in order to control energy systems incorporating renewable and electrochemical sources, particularly Proton Exchange Membrane (PEM) fuel cells. The main issue here is, to control the incoming hydrogen and oxygen flows to the electrodes based on a fuel cell bond graph model developed under 20-sim software and to regulate the output current delivered by the fuel cell while respecting its static characteristic curve and by adjusting the oxygen flow at the cathode and the hydrogen flow at the anode.
\end{abstract}

Keywords: PEM Fuel Cell, Bond Graph, Hydrogen and Oxygen Flows, PID Controller, Simulation

\section{Introduction}

The development of new energy sources is a major challenge of the 21 st century to get alternatives to fossil energies that have negative impacts on the environment. The policy of reducing greenhouse gas emissions is closely related to the production and consumption of energy; it is in this way that research on renewable energy has seen an interest by its inexhaustible and clean character (Solomon and Krishna, 2011). Therefore, a great small-scale development of renewable energy has taken place such as thermal or photovoltaic solar systems, wind turbines, micro hydraulic, geometrical heat pumps and fuel cells.

Renewable energy systems based on hydrogen, on the one hand, are faced with global warming and, on the other hand, are an innovative solution to the energy storage problem. The hydrogen technologies and especially the low temperature fuel cells replace many assets to be the energy generators of the future. Hydrogen seems as a very serious element, even if it is only an energy carrier, not a primary resource. This gas replaces batteries for electricity storage in the longterm and allows, on one side to meet the requirements of energy consumers and on the other to overcome the randomness of these production modes. Today manufacturers consider fuel cells as an attractive alternative to the conventional energy sources in which they participate and invest in the development of this low emission technology of harmful gases.
With advances in the field of materials technology as well as significant investments in various sectors such as cogeneration and the automotive industry, new perspectives appear to produce clean electrical energy through the fuel cell. To use this device in the best and most efficient way, the detailed knowledge of its operation is necessary. Since it has a large number of parameters to be controlled simultaneously (temperature, membrane humidification, gases flow...), the use of a fuel cell is particularly complicated.

Different types of fuel cells (Larminie and Dicks, 2003; Kordesch and Simader, 1996; Hirschenhofer et al., 1998) operate at temperatures ranging from a few tens of degrees Celsius to over $1000^{\circ} \mathrm{C}$ according to the used electrolyte. This manuscript focuses on Proton Exchange Membrane Fuel Cell (PEMFC) wherein the used electrolyte has a solid nature "Nafion" and operates at low temperatures (between 40 and $90^{\circ} \mathrm{C}$ ).

Since the very early development, the control of fuel cells has caught the attention of many authors (Biyikoglu, 2005; Caux et al., 2005; Amphlett et al., 1995a; 1995b). Different approaches for fuel cell models are found in the literature (Wahdame et al., 2006; Candusso et al., 2002; Pukrushpan et al., 2002).

The paper is structured as follows: In the first part, a general overview of the PEM fuel cell is provided, a brief description of the various phenomena that occur within the fuel cell will be given; a PEM fuel cell bond graph model will be presented also. The second part will be devoted to explain the appropriate 
methodology to control the gases flows, to justify the use of the PID controller which, in turn, will act on the solenoid valve (anode side) and the compressor (cathode side) to provide the desired pressure of the used gases. Finally, the paper will focus on the control implementation of incoming gases in the fuel cell; simulation and experimental results are presented: They show a very good agreement. The last part will be devoted to conclude the work.

\section{Fuel Cell Principle}

The fuel used in most fuel cells is the hydrogen. The fuel cell is an electrochemical converter which converts the chemical energy of a liquid or gaseous fuel into electrical energy. It involves the oxidoreduction reaction between hydrogen and oxygen to produce water, electricity and heat.

In 1802, Sir Henry David sets out the principle of reverse electrolysis (Larminie and Dicks, 2003). He demonstrated the possibility to produce electricity and heat from the chemical reaction between oxygen and hydrogen (Hoogers, 2002). Based on this process, Sir William Grove described in 1839 the first fuel cell operating with hydrogen and oxygen, at low temperatures, with platinum electrodes and sulfuric acid as electrolyte. In the 1960 and $1970 \mathrm{~s}$, fuel cells have been the subject of numerous studies that led to space applications: Electrical energy supply of Gemini capsules (PEM fuel cell), Apollo (alkaline fuel cell) and the space shuttle. In the early $1970 \mathrm{~s}$, the PEM fuel cell technology has developed significantly. It's really in the early $1990 \mathrm{~s}$ that the fuel cells have gained a renewed interest by the realization of different prototypes in many fields such as stationary, portable, aviation, automobiles etc.

The fuel cell consists of an electrolyte layer in contact with two electrodes (anode and cathode) on either side. As we have mentioned, a fuel cell is an energy conversion device that converts the chemical energy of a reaction directly into electricity, water and heat. The electrochemical reactions involved in the anode and cathode and its overall reactions can be formulated as follows.

Anode side:

$$
H_{2} \rightarrow 2 H^{+}+2 e^{-}
$$

Cathode side:

$$
2 \mathrm{H}^{+}+2 e^{-}+\frac{1}{2} \mathrm{O}_{2} \rightarrow \mathrm{H}_{2} \mathrm{O}
$$

Overall reaction:

$$
\mathrm{H}_{2}+\frac{1}{2} \mathrm{O}_{2} \rightarrow \mathrm{H}_{2} \mathrm{O}+\text { Electricit } y+\text { Heat }
$$

These opposed electrochemical processes are the source of a potential difference between the electrodes supplied with reagents. The manufacturers assemble several electrochemical cells in series to obtain a sufficiently high voltage in order to treat it with a satisfactory performance.

The study of fuel cells and especially those of PEM technology reinforced the need to take into account many problems, among which stand out the control of hydrogen and oxygen incoming at the electrodes (Springer et al., 1991). The following section will be devoted to the control of gases flows and the choice of the controller in relation with the PEMFC bond graph model in order to ensure a proper operation and to improve its performances.

\section{The Adopted Control Description}

The control of fuel cells remains delicate because of the large number of physical parameters involved. Therefore, it is not easy to establish relationships between causes that may have an influence on the system (factors) and the measurable effects (answers), nor find out if there are interactions between factors.

The retained problem for the fuel cell is the gases storage (hydrogen and oxygen) in a tank and its operating mode, also the value of the produced voltage or current is related to the used amount of gases, so it is necessary to improve the complete system performance by an optimal control of the fuel cell. The hydrogen (anode side) and oxygen (cathode side) required to the fuel cell operation are provided under a determined pressure (or flow).

The complete system is necessarily equipped with many sensors of flows, pressures, temperatures, humidification, amperage, voltage, hydrogen concentration, etc., that must be continuously analyzed to control the various components, as well as the start-up and the shutdown procedures, either voluntarily or emergency; a set of control command ensure these functions.

The fuel cell system is composed of three subsystems, a cathode part, an anode part and a thermal common part:

- The cathode part should control the air pressure and flow at the compartment inlet

- The anode part imposes the hydrogen (stored in a tank) pressure at the compartment inlet through a solenoid valve controlled by a regulator

- The thermal part must maintain and limit the stack temperature

In this manuscript, we will focus on the Fuel Cell System part shown in Fig. 1 and we will design the control of incoming hydrogen and oxygen flows. 


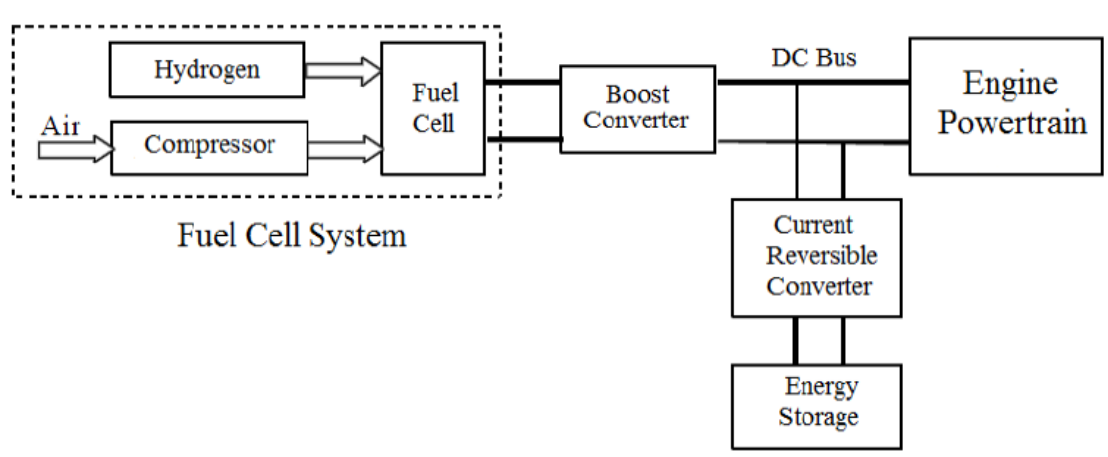

Fig. 1. Fuel cell hybrid electric power train (energy storage)

\section{Anode Input-Output Conditioning}

The fuel used in the PEMFC is the hydrogen, it can be stored in a tank or produced from a hydrocarbon, usually methanol, through a reformer. A pure hydrogen supply allows the energy amount optimization. The hydrogen management system is composed of several auxiliaries such as the solenoid valve which ensures a well determined gas pressure to the anode; this pressure has an influence on the fuel cell efficiency. For a proper pressure control, a controller may influence on the valve operation, i.e., on the valve opening.

The stack is supplied with hydrogen through a control system which imposes the desired flow (or else the desired power) under a pressure substantially equal to the cathode pressure in order to limit the transverse mechanical efforts on the electrolyte membrane.

\section{Cathode Input-Output Conditioning}

The oxygen is one of the required vectors for the fuel cell operation. The PEM fuel cell is supplied either directly with pure oxygen stored under pressure in a tank either through the air. The air management system is ensured by a compressor (or blower) whose block diagram is shown in Fig. 2. The choice of the operating pressure affects the electrochemical conversion performance, the reagents humidification process and the compressor energy consumption. An operation at high pressure helps achieve high power densities for the stack; it also facilitates water and heat management. The use of an expansion turbine at the cathode outlet may allow to recover a part of the compression energy. The operation at low pressure leads to a voltage efficiency less good and increases the capacity of the entire humidification/condensation. On the other side, at low pressure, the compressor consumption is reduced (M'boua, 2010). Indeed, the pressure and the flow must be controlled in order to ensure the stack needs. The air is evacuated from the cathode generally saturated with moisture in presence of a stream of liquid water.

\section{Description of the PEMFC Auxiliaries to be Controlled}

\section{The Valve}

A valve is a device used to stop or change the flow of a liquid or gaseous fluid. Valves can be classified in different categories according to their characteristics:

- By size: From the simple little tap to the very large valve controlling the incoming water flow in a hydroelectric power station

- By the function: Flow control valve, shut-off valve, drain valve, etc

- By the obstacle principle to the employed flow: butterfly valve, guillotine valve, etc

- By the control system: Manual, electric (solenoid valve), hydraulic, pneumatic, etc

\section{The Air Compressor}

The air system supplies with oxygen the different reactors of the power module (stack cathode and reformer) from the filtered ambient air.

The compressed air is obtained through a compression system which can provide a flow of up to $0.1 \mathrm{~kg} \mathrm{~s}^{-1}$ with a pressure level of up to 4.5 bars depending on the operating point.

\section{Control Type to be Used}

The most industrial processes require to control a number of parameters such as temperature, pressure, flow, level, concentration etc. The control objective is to ensure the process operation according to predefined criteria by specifications. The required qualities most encountered industrially are the stability, the accuracy and the rapidity.

PID controllers are widely used and suitable for about $80 \%$ of control loops. For the remaining $20 \%$, it is necessary to have recourse to controls of advanced type for which the modeling process is essential. 


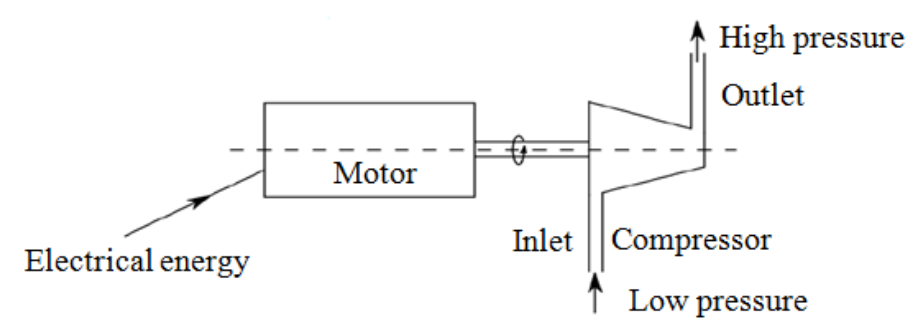

Fig. 2. The compressor block diagram

The adjustment of a PID controller requires the determination of the coefficients $G, \tau_{i}$ and $\tau_{d}$ in order to obtain an adequate response of the process and the control. The objective is to ensure robustness, rapidity and accuracy (Pukrushpan et al., 2002).

In the following section an approach to implement the bond graph model of the adapted control of incoming gases flow, using 20-sim software (Kleijn, 2009), will be proposed; simulations results will be presented.

\section{Design and Simulation of the Control}

\section{Control Design}

The design of piloted energy systems involving multiple physical domains (mechanical, hydraulic, electrical, etc.) requires the use of a common design tool taking into account the dynamic and energetic aspects.

The bond graph (Thoma and Ould Bouamama, 2000; Karnopp et al., 2012) tool is a unified graphical language for all areas of engineering sciences and confirmed as a structured approach for modeling and simulation of multidisciplinary systems. The modeling of a technical system with bond graph does not require the writing of general conservation laws; it is based mainly on the characterization of energy exchange phenomena within the system.

In process engineering, the use of the true bond graph introduces thermal and chemical effort variables (entropy, chemical potential) which are complex and inappropriate for simulation problems since they obey no law of simple conservation. A pseudo-bond graph (Karnopp and Azarbaijani, 1981; Karnopp, 1978) for which the product of the effort and flow variables no longer has the dimension of power is then introduced to their modeling. However, it should be noted that the classical properties of a true bond graph remain valid for a pseudo bond graph (causality, setting in equation, etc.).

\section{Control Implementation}

The anode and cathode compartments of the fuel cell serve to supply the electrodes in fuel (H2) and oxidant (O2). To represent variations in fluids composition (oxygen and hydrogen fractions) between stack inputs and outputs, the fuel cell system control must be applied to the two parts of the system, namely:

- In the cathode part, the air flow and the pressure at the compartment inlet should be controlled

- In the anode part, in the presence of a pressurized hydrogen tank, a device should be placed to control the pressure in the inlet compartment

Valve Control at the Anode Side: Implementation of the PID Controller

The anodic system consists of two mechanical actuators (regulator and valve) and a recirculation system. The purpose of the anode system is to supply the fuel cell with hydrogen. This subsystem can be represented by the scheme given in Fig. 3.

The anode part of the fuel cell is supplied with hydrogen through a valve connected to a tank. The hydrogen pressure should be controlled to get the desired response. The transfer function of the valve model is given by:

$T F_{\text {Valve }}=\frac{K_{V}}{1+\tau \cdot p}$

Where:

$\tau=$ A time constant, typically $0.15 \mathrm{~s}$ and

$K_{V}=$ The valve static gain.

Figure 4 shows the open loop PEM fuel cell model supplied with hydrogen through a solenoid valve.

The hydrogen distribution is well controlled since the pressure in the inlet compartment is kept constant despite the power demands. This control type is particularly suitable for pressurized storage systems. Figure 5 shows the closed loop PEM fuel cell model controlled by a solenoid valve and a controller.

\section{Compressor Control at the Cathode Side: Implementation of the PID Controller}

It is necessary to control the compressor flow to ensure a constant stoichiometric ratio and to enable the system to follow the required power profile to the stack system. A constant inlet pressure must be maintained into the compartment since it sets the compressor operating point and the hydration system. This subsystem can be represented by the scheme given in Fig. 6 . 


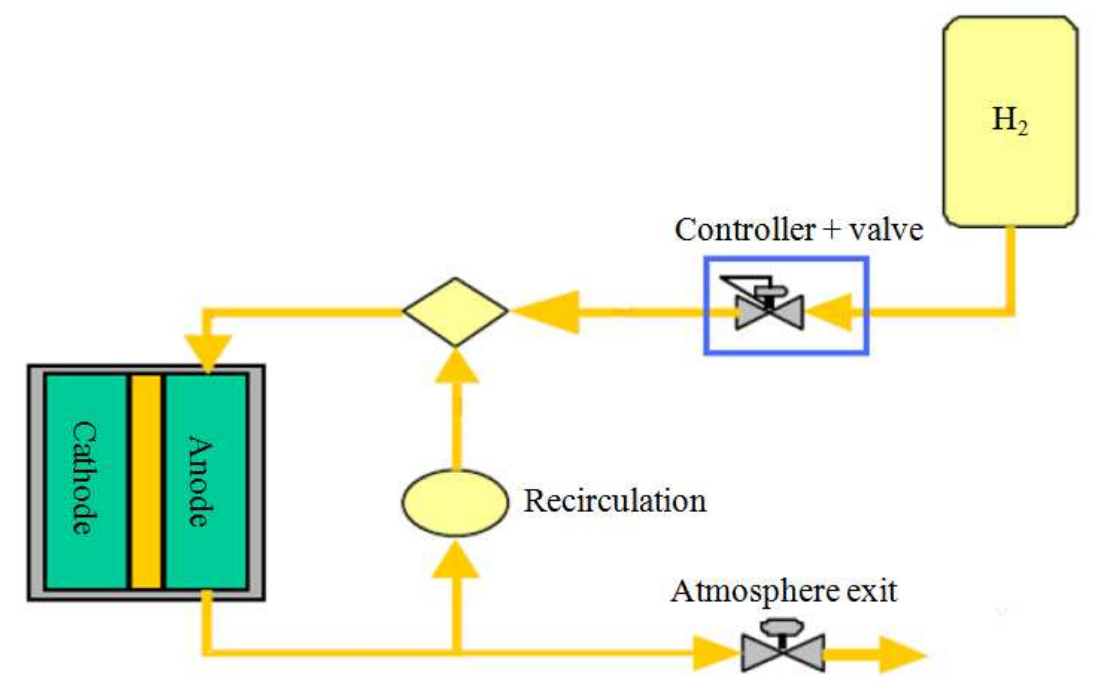

Fig. 3. Anodic system

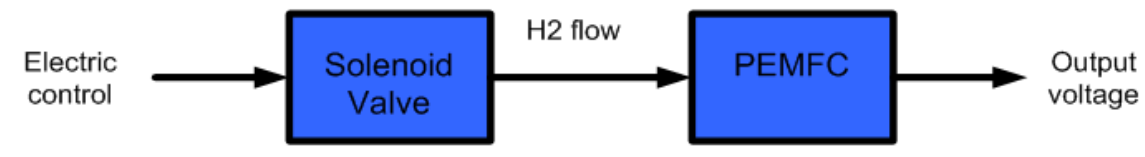

Fig. 4. PEM fuel cell supplied with hydrogen flow through a valve (open loop)

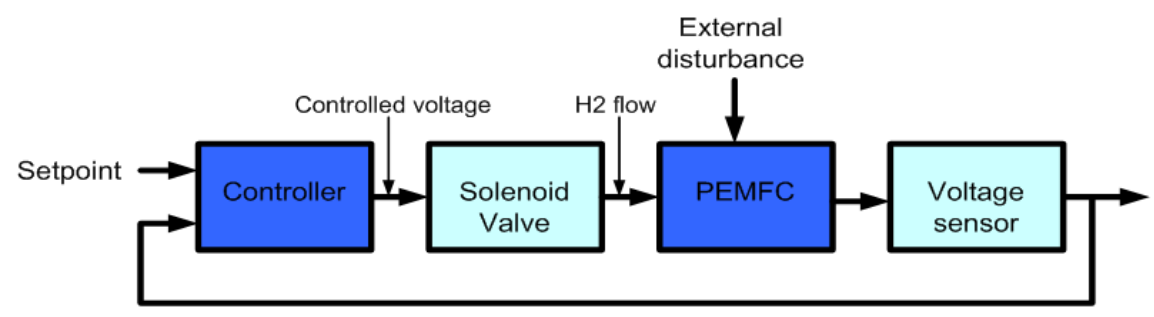

Fig. 5. PEM fuel cell controlled by a valve and a controller (closed loop)

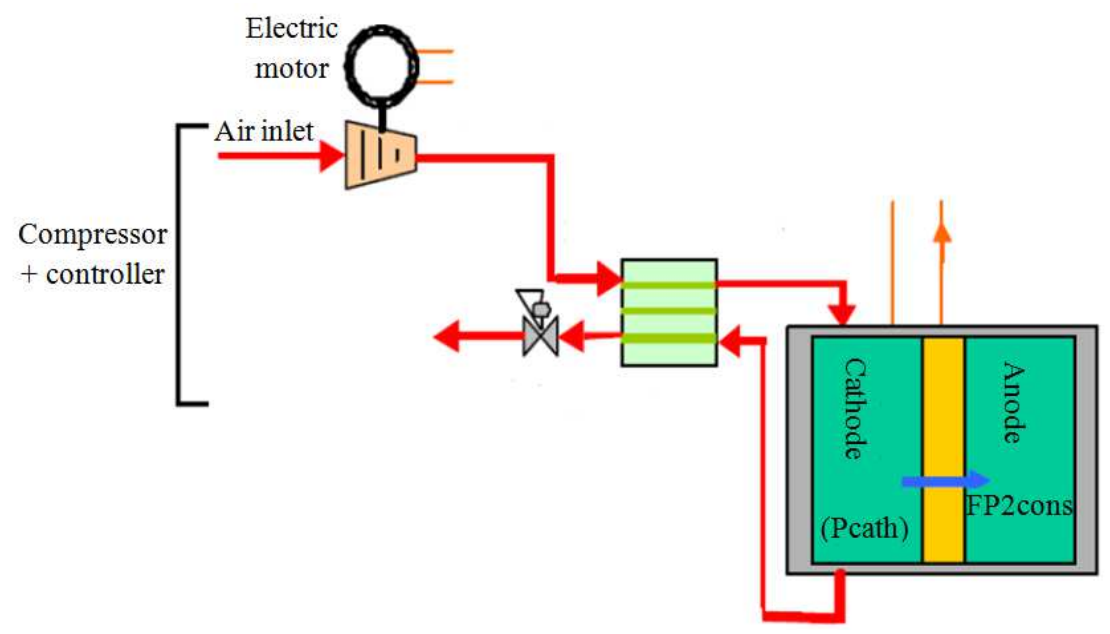

Fig. 6. Cathodic system 
The compressor is used in the conditioning circuit of the incoming air in the cathode compartment of the fuel cell. The compressors used in this type of applications are those that easily allow the control of the output flow. The transfer function of the compressor model is given by:

$$
T F_{\text {Comp }}=\frac{K_{\text {error }}}{1+\tau \cdot p}
$$

Where:

$\tau=$ A time constant imposed by the speed loop, typically $0.5 \mathrm{~s}$ and

$K_{\text {error }}=$ The linearization error with $0.8<K_{\text {error }}<1.2$

Figure 7 shows the open loop PEM fuel cell model supplied with oxygen flow through a compressor.

In order to implement the controller, the precision required for the knowledge of the compressor output flow should be estimated. Figure 8 shows the closed loop PEM fuel cell model controlled by a compressor and a controller.

\section{Control of the PEM Fuel Cell Bond Graph Model}

The purpose of this manuscript consists in controlling the incoming gases flows to the electrodes based on a PEM fuel cell bond graph model which can be easily expanded as required.

The principal assumptions used to model the PEM fuel cell are given as follows:

- $\quad$ 1-D modeling

- $\quad$ The gases used for chemical reactions are pure $\mathrm{O}_{2}$ and pure $\mathrm{H}_{2}$

- The electrodes are separately modeled

- No parasitic reaction

- The model describes the normal operating conditions

- Diffusion phenomena are only considered at the cathode side, where they are supposed to be the most important; they are neglected at the anode side

- $\quad$ No aging

The PEM fuel cell should be fitted with a solenoid valve and a compressor, both are controlled by a PID regulator, respectively at the anode and cathode side. The controller parameters will be determined using one of the existing methods that can be adopted to calculate the control parameters of the PID actions. Many methods are based on the loop response to the step (step response) and on experimental tests. The choice falls on Ziegler and Nichols method: It requires the observation of the process response and the knowledge of the controller structure. It is a method which calculates the PID actions, without the determination of the process parameters. Most methods to get the controller parameters consist in performing calculations on response curves of the open loop process, which is the PEM fuel cell model in our case, after applying a step signal, as shown in Fig. 9.

First, we consider the linear region of the response curve where the nominal voltage value is situated by applying different pressure. Secondly, we plot a straight line of this linear region and we focus on its point of intersection with the x-axis (time axis) to get the time $T_{U}$. Then, we define the time $T_{G}$ as the time taken for the controlled variable to vary with the same amplitude as the controller output. These two parameters $\left(T_{U}, T_{G}\right)$ are used to define the controller parameters.

Ziegler and Nichols (1993) in open loop make no assumption a priori on the loop behavior. For a used controller, the gain and coefficients values recommended by Ziegler and Nichols are given in Table 1 .

By applying different pressures of hydrogen and oxygen, the nominal voltage of each process response in open loop is taken, then the curve is plotted to determine finally the parameters $T_{U}$ and $T_{G}$.

For the PID controller used in the PEM fuel cell model, the nominal voltages values for different pressures are given in Table 2.

After tracing the nominal voltage curve versus time, the values of $T_{U}$ and $T_{G}$ can be determined, as mentioned below:

$$
T_{U}=5 \mathrm{~s} \text { and } T_{G}=3 \mathrm{~s}
$$

According to the values proposed by Ziegler and Nichols in Table 1, the coefficients $G_{r}, T_{i}$ and $T_{d}$ can be determined as follows:

$$
G_{r}=1.27 \times \frac{T_{G}}{T_{U}}
$$

$T_{i}=2 \times T_{U}$

$T_{d}=0.5 \times T_{U}$

$G_{r}=0.67, T_{i} 10 \mathrm{~s}$ and $T_{d}=2.5 \mathrm{~s}$.

After determining the setting parameters, these values are introduced in the regulators blocks of the anode and cathode sides in closed loop as shown in Fig. 10.

As mentioned previously, the purpose of this manuscript is to control the hydrogen and oxygen flows incoming to the PEM fuel cell. For this, a fuel cell model is needed that's why a detailed bond graph model of a Nexa PEM fuel cell developed under 20sim was provided. 


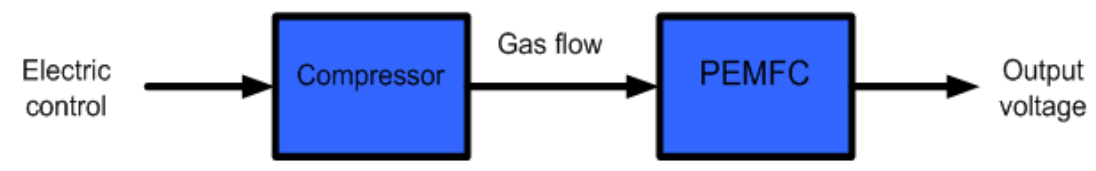

Fig. 7. PEM fuel cell supplied with oxygen flow through a compressor (open loop)

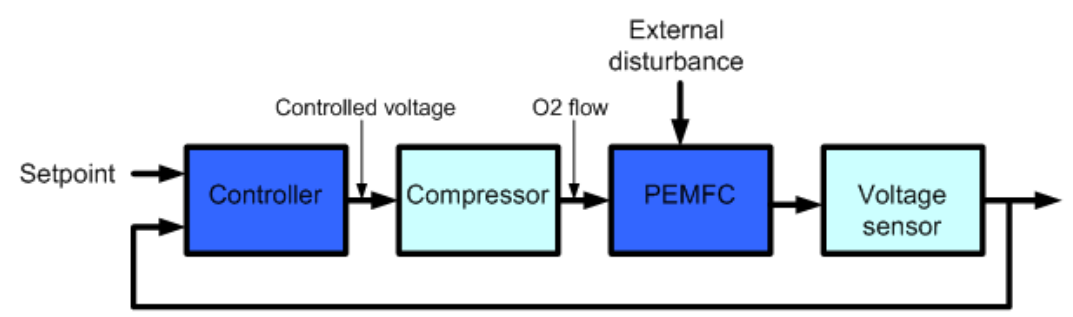

Fig. 8. PEM fuel cell controlled by a compressor and a controller (closed loop)

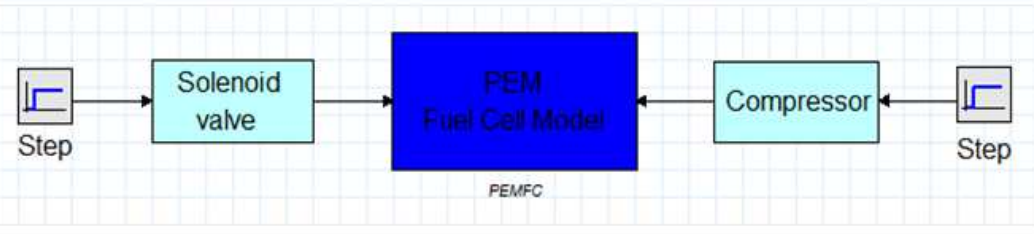

Fig. 9. 20-sim PEM fuel cell model in open loop

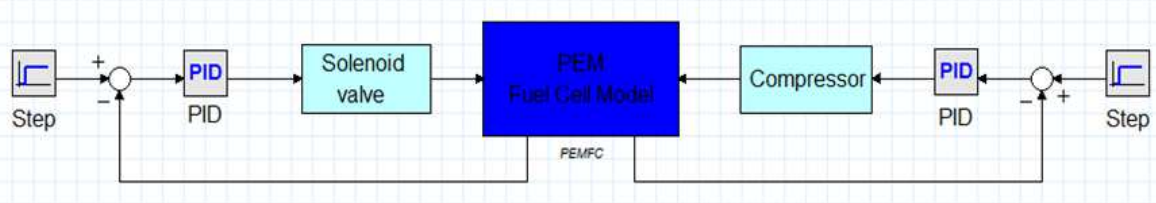

Fig. 10. 20-sim PEM fuel cell model in closed loop

Table 1. Proposed values by Ziegler and Nichols

\begin{tabular}{ll}
\hline Controller & Tuning parameters \\
\hline $\mathrm{P}$ & $G_{r}=\frac{T_{G}}{T_{U}}$ \\
$\mathrm{PI}$ & $G r=0.9 \times \frac{T_{G}}{T_{U}}$ \\
& $T_{i}=3.3 \times T_{U}$ \\
& $G r=1.27 \times \frac{T_{G}}{T_{U}}$ \\
PID & $T_{i}=2 \times T_{U}$ \\
& $T_{d}=0.5 \times T_{U}$ \\
\hline
\end{tabular}

Table 2. Nominal voltage values for different pressures.

\begin{tabular}{lc}
\hline Nominal voltage & Time \\
\hline 0.79 & 3.01 \\
0.79 & 3.09 \\
0.79 & 3.20 \\
0.76 & 3.50 \\
0.74 & 3.79 \\
0.71 & 3.96 \\
0.70 & 4.03 \\
\hline
\end{tabular}

The 20-sim software (Kleijn, 2009; Broenink, 1999) (University of Twente, Enschede, Netherlands) is a modeling and simulation program for dynamic multidomain systems such as electrical, mechanical and hydraulic systems or any combination of these. Its use is rather simple and direct, since we did not have to describe the equations by means of complex diagrams as in the case of Matlab Simulink. 20-sim tries to solve algebraic loops by iteration when they occur. It contains sophisticated algorithms to find analytic solutions.

The overall phenomenological model covers and tightly couples chemical, electrical and thermal fields in energy terms. The developed model recalls the physical structure of a real stack with two global equivalent dissociated and non-symmetrical electrodes. The Nexa system is composed of 47 elementary cells in series; it provides up to 1200 watts of unregulated DC power at a nominal output voltage of 26 VDC. The Nexa PEM fuel cell bond graph model is given by Fig. 11 .

As shown in Fig. 12, the PEM fuel cell bond graph global model contains a thermal bond graph model associated to that given in Fig. 11. 


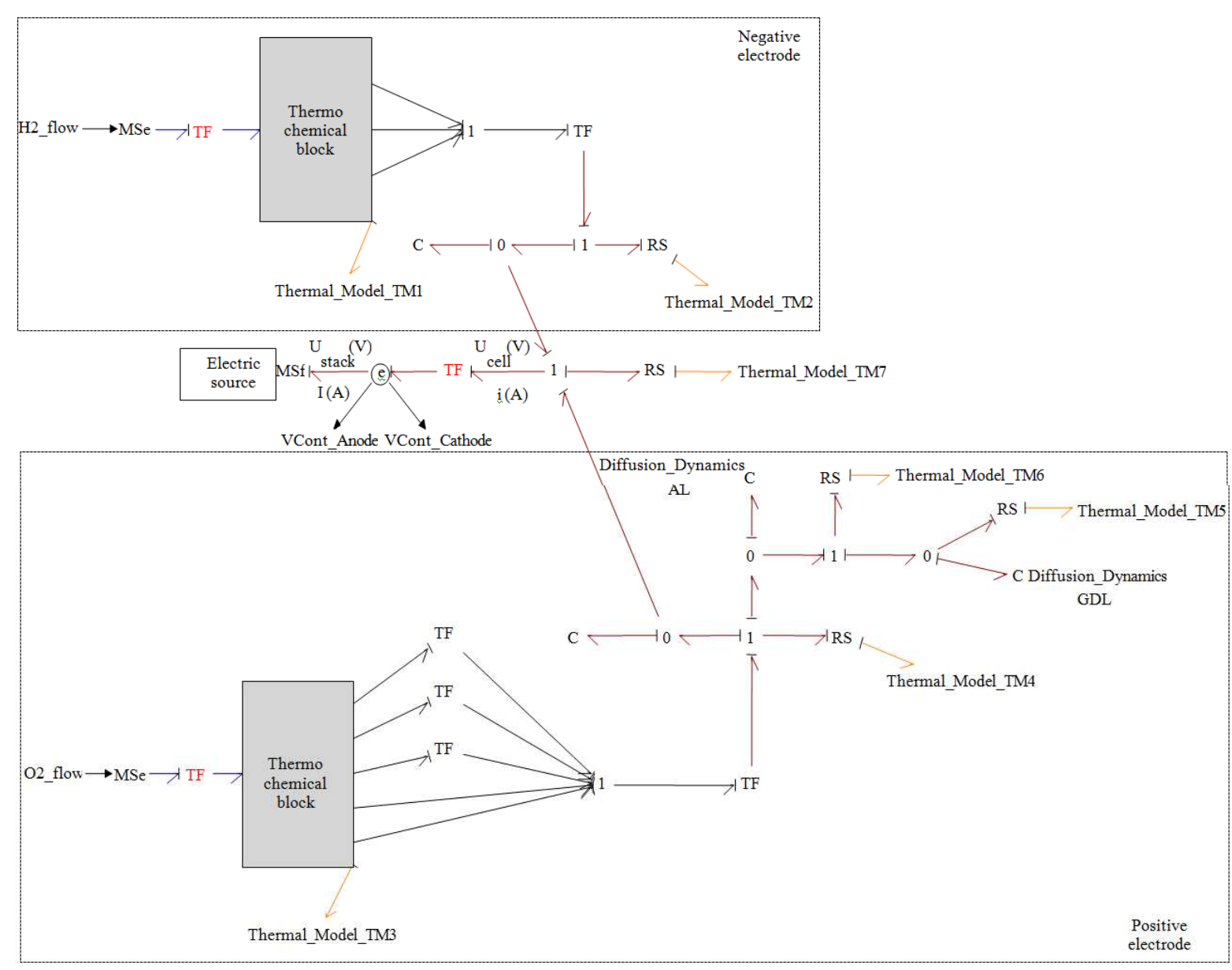

Fig. 11. The Nexa PEM Fuel cell bond graph model

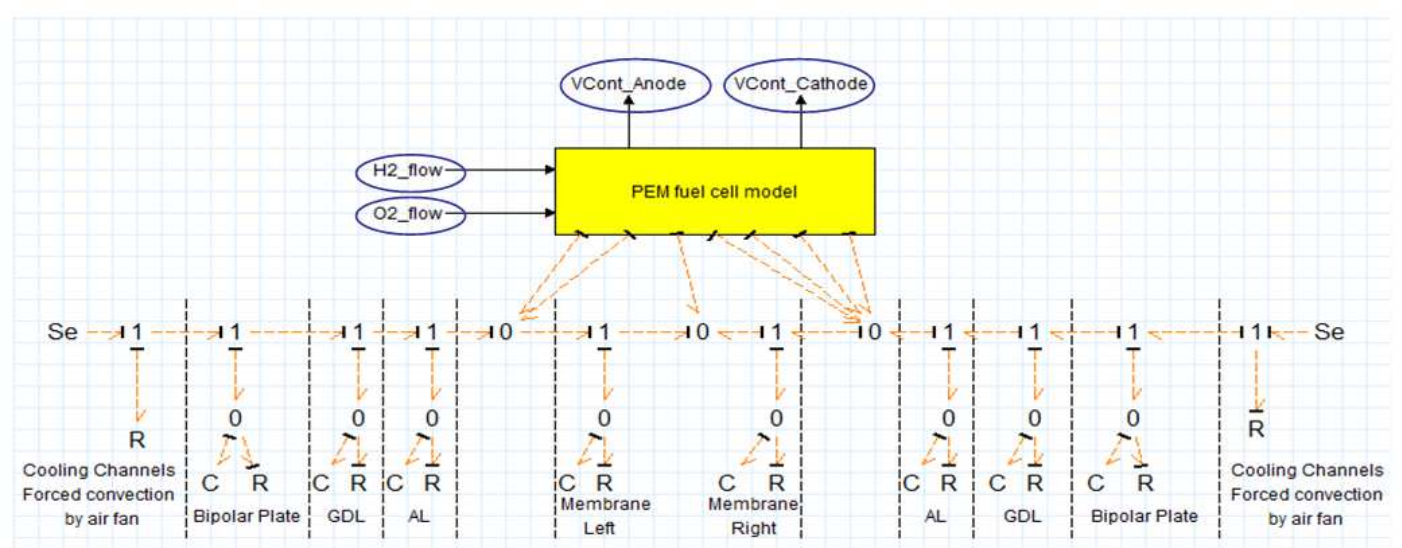

Fig. 12. The bond graph global model of the PEM fuel cell

\section{Results and Discussion}

Figure 13 shows a PEM cell polarization curve without and with regulators.

When the performance in voltage is reduced, the intensity is not equal to zero and over voltages, at the electrodes and in the membrane, appear due to charge transfer and species diffusion phenomena. The stack terminal voltage will be reduced due to different voltage drops: Activation, ohmic and diffusion over voltages. The fuel cell performance in voltage is high compared to that of a motor. 
The pressure difference between the anode and cathode can degrade the fuel cell and shorten its life, which leads us to keep the same value at the anode and cathode as shown in Fig. 14 and 15, where the curves representing the pressures of hydrogen and oxygen versus the time are given. This is a very important aspect of the fuel cell and membrane protection. During the chemical reaction, an interaction between the hydrogen and oxygen flows occurs within the fuel cell.

What is noticeable in this section is that the current delivered by the PEM fuel cell is related to the incoming gases flows, its variation is proportional to the hydrogen and oxygen flows as shown in Fig. 16 and 17. A high flow of hydrogen leads to a significant intensity of current.
The number of cells affects the amount of used gases. It is one of the most important parameters in the evolution of the system behavior which directly affects the fuel cell efficiency.

Simulations performed with three different pressures have led to the characteristics shown in Fig. 18, it can be seen that simulation results of the Nexa fuel cell model agree well with the measured data carried out by (Moreira and da Silva, 2009) shown in Fig. 19.

As shown in Fig. 18 and 19, a pressure increase leads to a voltage increase of the fuel cell. Theoretically, the increase in reagent concentration is related to the increase in pressure, which leads to an augmentation of the exchange current density.

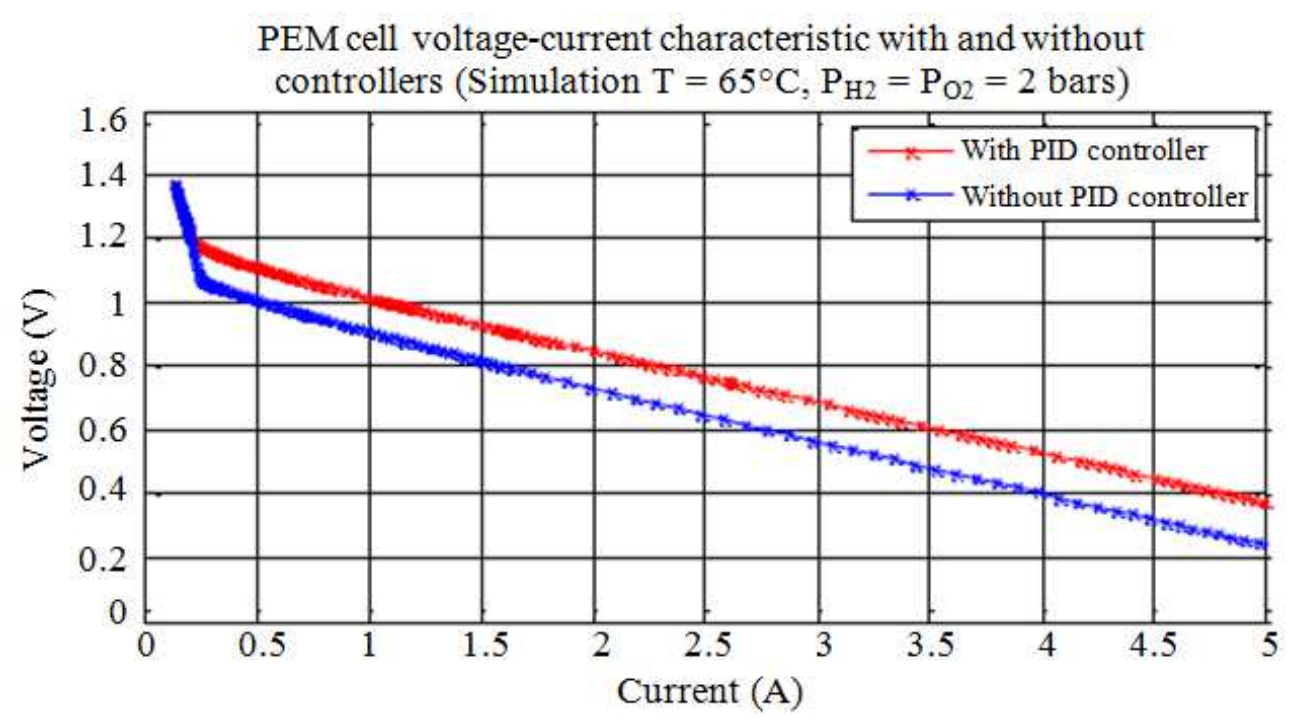

Fig. 13. Polarization curve of a Nexa cell with and without PID controllers

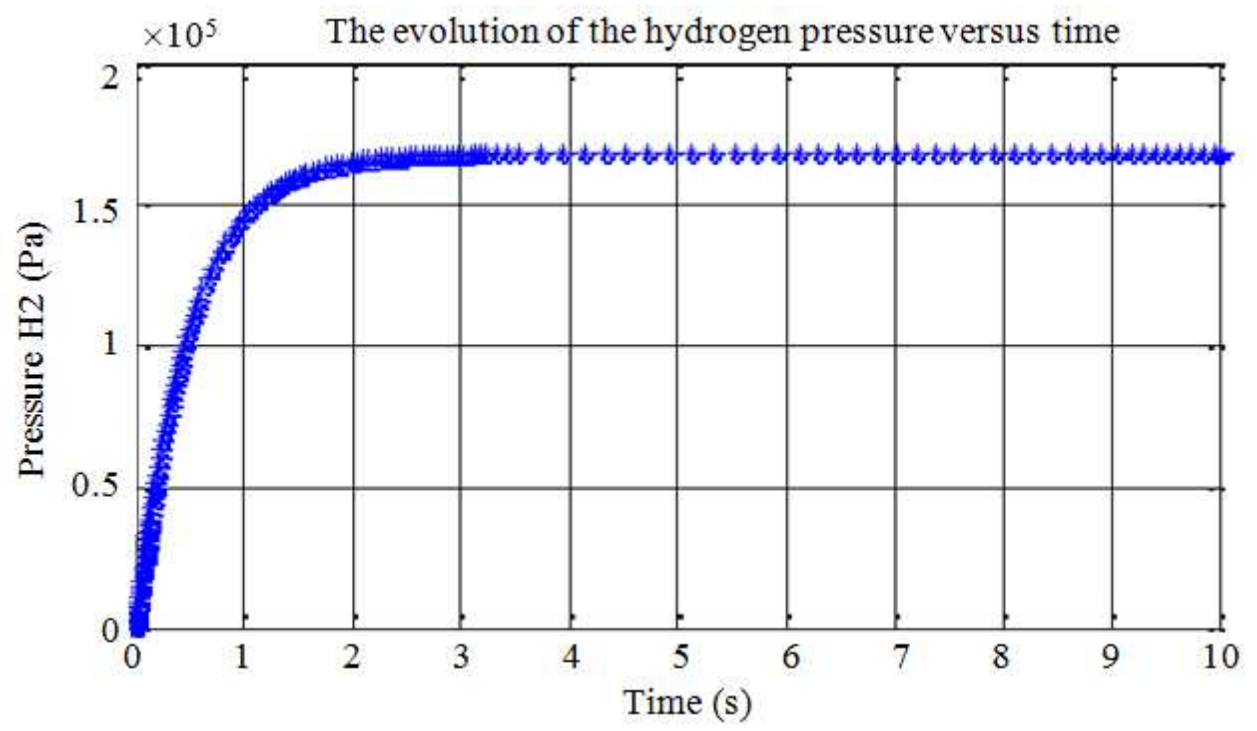

Fig. 14. Curve representing the evolution of the hydrogen pressure versus time 


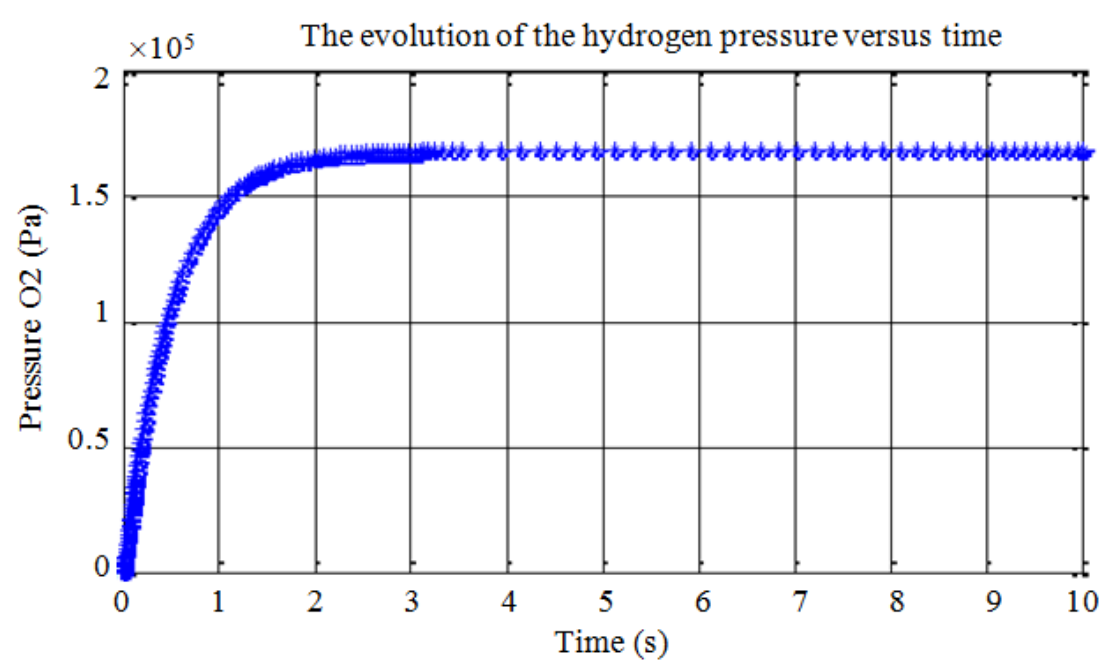

Fig. 15. Curve representing the evolution of the oxygen pressure versus time

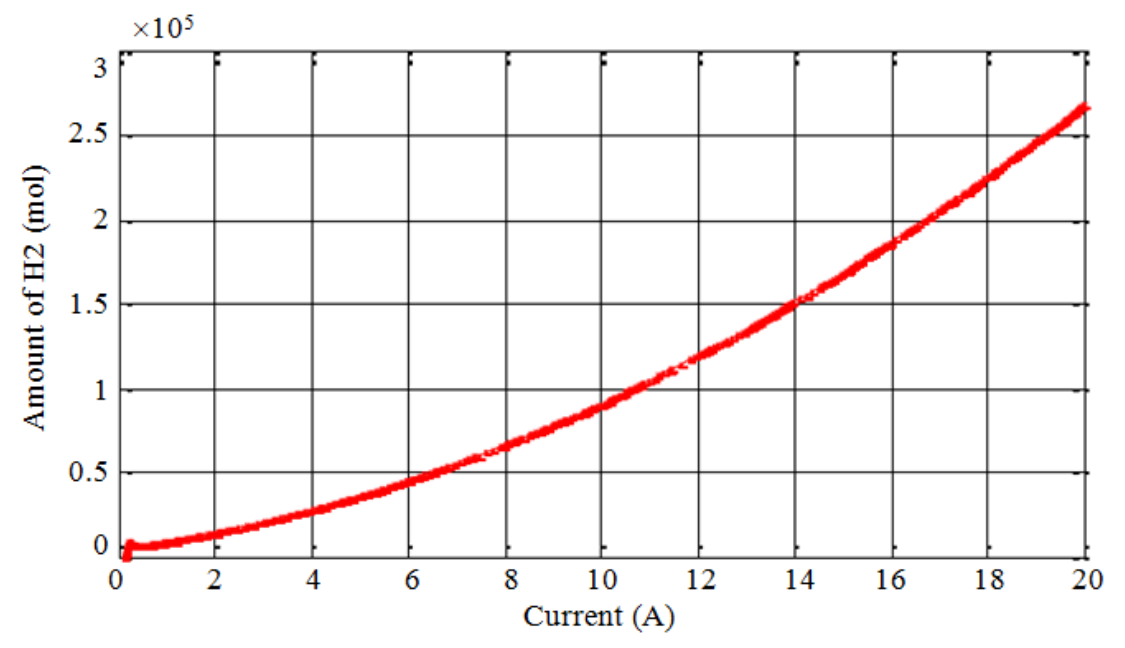

Fig. 16. Variation of the hydrogen amount versus the current

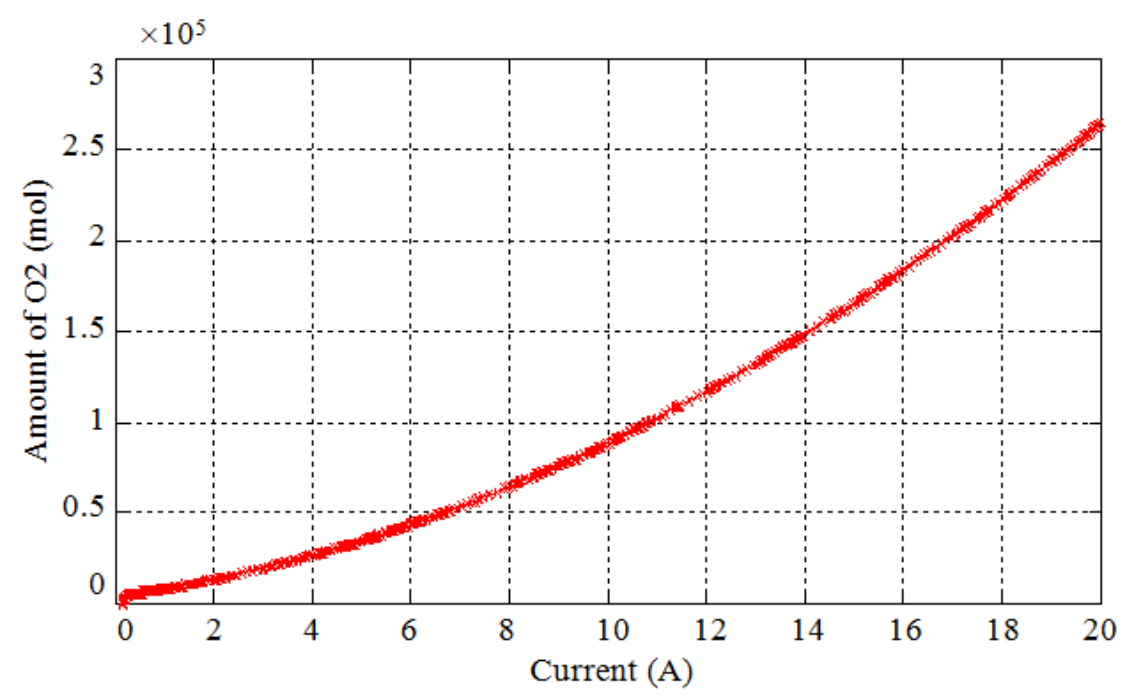

Fig. 17. Variation of the oxygen amount versus the current 


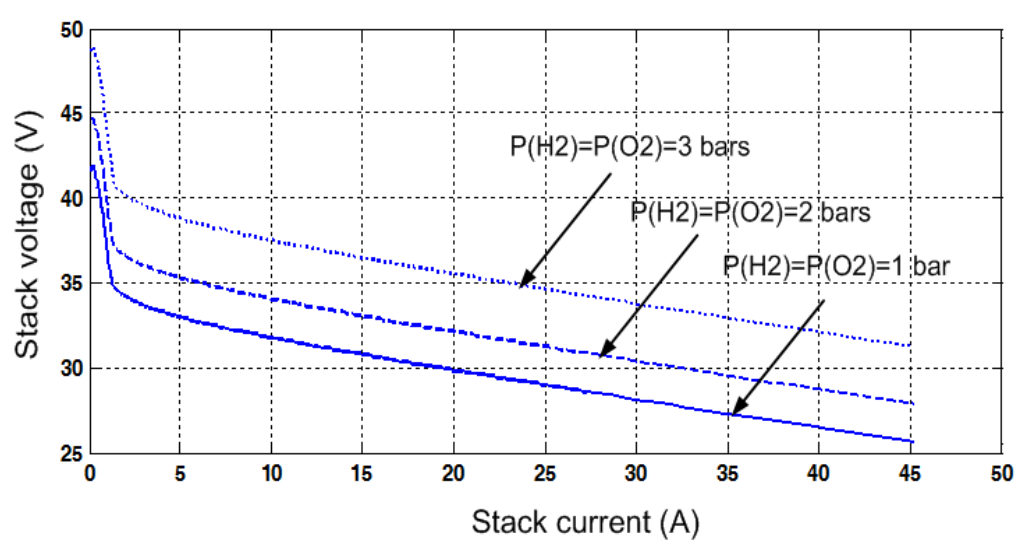

Fig. 18. Simulated polarization curves for three different hydrogen and oxygen pressures: $\mathrm{P}(\mathrm{H} 2)=\mathrm{P}(\mathrm{O} 2)=1$ bar $($ solid line $)$; $\mathrm{P}(\mathrm{H} 2)=$ $\mathrm{P}(\mathrm{O} 2)=2$ bars (dashed-line); and $\mathrm{P}(\mathrm{H} 2)=\mathrm{P}(\mathrm{O} 2)=3$ bars (dash-dotted line)

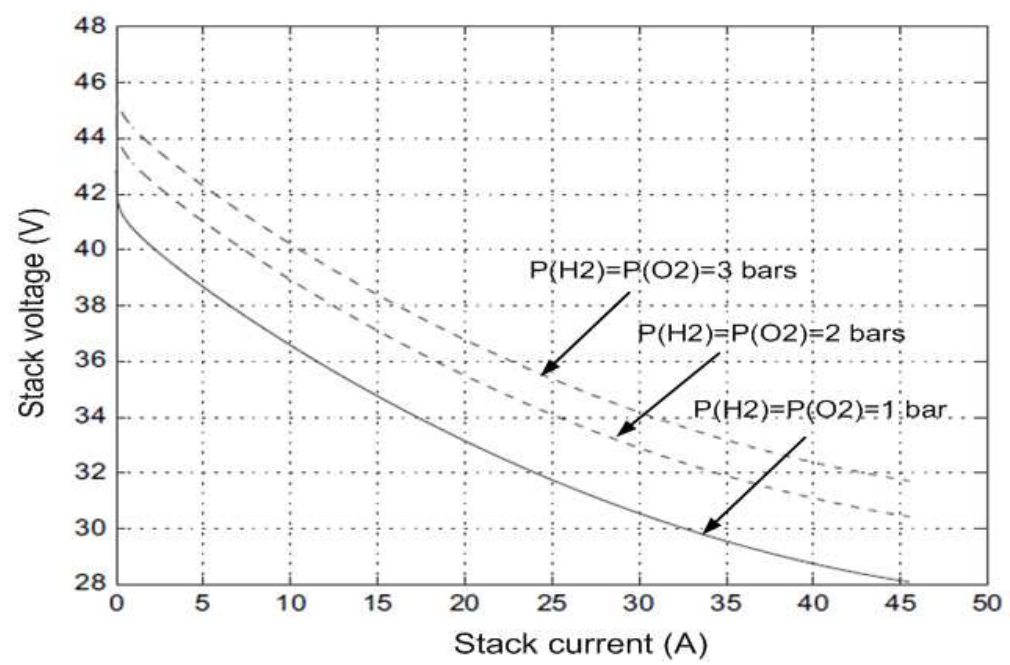

Fig. 19. Experimental polarization curves for three different hydrogen and oxygen pressures: $\mathrm{P}(\mathrm{H} 2)=\mathrm{P}(\mathrm{O} 2)=1$ bar $($ solid line); $\mathrm{P}(\mathrm{H} 2)=\mathrm{P}(\mathrm{O} 2)=2$ bars (dashed-line); and $\mathrm{P}(\mathrm{H} 2)=\mathrm{P}(\mathrm{O} 2)=3$ bars (dash-dotted line)

\section{Conclusion}

This manuscript has focused on the study and implementation of controllers on both sides of the PEM fuel cell. As a first step, we have reminded the principle operation of the PEM fuel cell and its different auxiliaries. As a second step, we presented the bond graph model of the fuel cell, then we studied its responses in open loop in order to determine the parameters of the PID controllers. In a third step, we introduced the parameters values found in open loop using Ziegler and Nichols method into the PID controllers on both sides anode and cathode, to study the PEM fuel cell in closed loop. The controls carried out are effective, the stack inlet pressure is well controlled. There is an agreement between simulation results of the Nexa PEM fuel cell bond graph model and experimental data performed by (Moreira and da Silva, 2009; Kirubakaran et al., 2009) which confirms that the implemented control is robust and reliable.

\section{Acknowledgement}

We make a point of thanking all those who contributed and aided for this work especially the ACCS laboratory (ENIT-Tunisia), the Jean Lamour Institute (Nancy Lorraine University in France) and the DRIVE laboratory of the ISAT (Nevers-France).

\section{Funding Information}

This research received no specific grant from any funding agency in the public, commercial, or not-for profit sectors.

\section{Author's Contributions}

Dhia Mzoughi: Participated in all experiments, coordinated the data-analysis and contributed to the writing of the manuscript.

Nabila Khili: Participated in all experiments and coordinated the data-analysis. 
Hatem Allagui: Coordinated the work and contributed to the writing of the manuscript.

Abdelkader Mami: Designed the research plan and organized the study.

\section{Ethics}

This article is original and contains unpublished materials. The corresponding author confirms that all of the other authors have read and approved the manuscript and no ethical issues involved.

\section{References}

Amphlett, J.C., R.M. Baumert, R.F. Mann, B.A. Peppley and P.R. Roberge, 1995a. Performance modeling of the Ballard Mark IV solid polymer electrolyte fuel cell_I. Mechanistic model development. J. Electrochem. Soc., 142: 1-8. DOI: $10.1149 / 1.2043866$

Amphlett, J.C., R.M. Baumert, R.F. Mann, B.A. Peppley and P.R. Roberge, 1995b. Performance modeling of the ballard mark IV solid polymer electrolyte fuel cell II. Empirical model development. J. Electrochem. Soc., 142: 9-15. DOI: 10.1149/1.2043959

Biyikoglu, A., 2005. Review of proton exchange membrane fuel cell models. Int. J. Hydrogen Energy, 30: 1181-1212.

DOI: 10.1016/j.ijhydene.2005.05.010

Broenink, J.F., 1999. 20-sim software for hierarchical bond-graph/block-diagram models. Simulat. Practice Theory, 7: 481-492. DOI: $10.1016 / \mathrm{S} 0928-4869(99) 00018-\mathrm{X}$

Candusso, D., A. Walter, S. Bacha and E. Rullière, 2002. Modelling, control and simulation of a fuel cell based power supply system with energy management. Proceedings of the 28th Annual Conference of Industrial Electronics Conference, Nov. 5-8, IEEE Xplore Press, Sevilla, pp: 1294-1299. DOI: 10.1109/IECON.2002.1185462

Caux, S., J. Lachaize, M. Fadel, P. Schott and L. Nicod, 2005. Modelling and control of a fuel cell system and storage elements in transport applications. J. Process Control, 15: 481-491. DOI: $10.1016 /$ j.jprocont.2004.08.002

Hirschenhofer, J.H., D.B. Stauffer, R.R. Engleman and M.G. Klett, 1998. Fuel Cell Handbook. 4th Edn., Parsons Corporation, USA, pp: 268.

Hoogers, G., 2002. Fuel Cell Technology Handbook. 1st Edn., CRC Press, ISBN-10: 9780849308772, pp: 360.

Karnopp, D., 1978. Pseudo bond graphs for thermal energy transport. J. Dynamic Syst. Measure. Control, 100: 165-169. DOI: 10.1115/1.3426363

Karnopp, D. and S. Azarbaijani, 1981. Pseudo bond graphs for generalized compartmental models in engineering and physiology. J. Franklin Institute, 312: 95-108. DOI: 10.1016/0016-0032(81)90081-8
Karnopp, D.C., D.L. Margolis and R. Rosenberg, 2012. System Dynamics: Modeling, Simulation and Control of Mechatronic Systems. 5th Edn., John Wiley and Sons Inc, Hoboken, NJ, ISBN-10: $111816007 \mathrm{X}, \mathrm{pp}: 648$.

Kirubakaran, A., S. Jain and R.K. Nema, 2009. A review on fuel cell technologies and power electronic interface. Renewable Sustainable Energy Rev., 13: 2430-2440. DOI: 10.1016/j.rser.2009.04.004

Kleijn, C., 2009. Getting Started with 20-sim 4.1. 1st Edn., Getting Started with 20-sim, ISBN-10: 9079499064.

Kordesch, K. and G. Simader, 1996. Fuel Cell and Their Applications. 1st Edn., VCH Publications, New York, pp: 375.

Larminie, J. and A. Dicks, 2003. Fuel Cell Systems Explained. 2nd Edn., J. Wiley, Chichester, West Sussex, ISBN-10: 047084857X, pp: 406.

M'boua, J., 2010. Contribution to the modeling of compressors control-application to air management in PEM fuel cell systems. PhD. Thesis, Belfort Montbéliard University of Technology, France.

Moreira, M.V. and G.E. da Silva, 2009. A practical model for evaluating the performance of proton exchange membrane fuel cells. Renewable Energy, 34: 1734-1741. DOI: 10.1016/j.renene.2009.01.002

Pukrushpan, J.T., A.G. Stefanopoulou and H. Peng, 2002. Modeling and control for PEM fuel cell stack system. Proceedings of the American Control Conference, May 8-10, IEEE Xplore Press, Anchorage, AK, pp: 3117-3122. DOI: 10.1109/ACC.2002.1025268

Solomon, B.D. and K. Krishna, 2011. The coming sustainable energy transition: History, strategies and outlook. Energy Policy, 39: 7422-7431.

DOI: 10.1016/j.enpol.2011.09.009

Springer, T.E., T.A. Zawodzinski and S. Gottesfeld, 1991. Polymer electrolyte fuel cell model. J. Electro-chem. Soc., 138: 2334-2342.

DOI: $10.1149 / 1.2085971$

Thoma, J. and B. Ould Bouamama, 2000. Modelling and Simulation in Thermal and Chemical Engineering: A Bond Graph Approach. 1st Edn., Springer Science and Business Media, Berlin, ISBN-10: 3540663886, pp: 219.

Wahdame, B., D. Candusso and J.M. Kauffmann, 2006. Study of gas pressure and flow rate influences on a 500W PEM fuel cell thanks to the experimental design methodology. J. Power Sources, 156: 92-99. DOI: 10.1016/j.jpowsour.2005.08.036

Ziegler, J.G. and N.B. Nichols, 1993. Optimum settings for automatic controllers. J. Dyn. Sys., Meas., Control, 115: 220-222. DOI: 10.1115/1.2899060 